\title{
A reconstrução da formação médica nos novos cenários de prática: inovaçôes no estilo de pensamento biomédico
}

| ${ }^{1}$ Maria Inês Nogueira |

Resumo: Este artigo discute o processo de transformação da formação médica brasileira a partir da experiência de reforma curricular desenvolvida na escola médica da Universidade Federal Fluminense. Utilizou-se o referencial sócio-filosófico de Ludwig Fleck, partindo do pressuposto de que o olhar anatomoclínico orienta o estilo de pensamento biomédico. Considerou-se a hipótese de que a formação médica encontra-se estruturada entre dois polos (tecnocientífico e ético-humanista), com a valorização do primeiro, e o Sistema Único de Saúde (SUS) como superfície de emergência das mudanças na educação médica. Desenvolveu-se uma pesquisa de caráter etnográfico enfocando a disciplina Trabalho de Campo Supervisionado, com triangulação de métodos: observação participante dos cenários diversificados de aprendizagem nos dois primeiros anos de formação, entrevistas com alunos e preceptores e análise documental. Concluiu-se que a instituição de novos cenários de prática favorece a construção de um olhar ampliado dos estudantes sobre os usuários dos serviços de saúde, contribuindo para o resgate do polo ético-humanista da formação.

> Palavras-chave: formação médica; epistemologia; cenários de prática; Sistema Único de Saúde.

\author{
1 Departamento de \\ Planejamento em Saúde, \\ Instituto de Saúde Coletiva, \\ Universidade Federal \\ Fluminense. Niterói-RJ, \\ Brasil. Endereço eletrônico: \\ minogueira2@gmail.com
}

Recebido em: 06/04/2014. Aprovado em: 24/08/2014. 


\section{Introdução}

Com o surgimento da anatomoclínica, operou-se uma mudança de perspectiva fundamental no saber e na prática médica: surgiu a concepção de doença como expressão de lesões celulares e o ensino da medicina se tornou eminentemente hospitalar (CAMARGO JR., 2003). Na atualidade, em contraste com o desenvolvimento científico e tecnológico alcançado, a biomedicina encontra limitaçôes para atender às complexas necessidades de saúde do ser humano.

A articulação entre biomedicina, ciência e atenção à saúde se dá na interseção de dois campos: o tecnocientífico e o ético. Visto que a colonização científica do cotidiano é uma tendência preponderante da contemporaneidade, o campo de práticas da área da saúde, e da prática médica em especial, não foge a esse imperativo. Ao contrário, verifica-se cada vez mais uma reificação de artefatos produzidos pelas tecnobiociências que chegam a obscurecer a importância do polo ético na construção das práticas de saúde (CAMARGO JR., 2009).

Acredita-se que a instituição de novos campos de prática na formação médica possibilite uma reorientação do olhar sobre as dimensões subjetivas do adoecimento, oferecendo maior visibilidade às questôes sociais, culturais e psicológicas do indivíduo doente, numa compreensão ampliada do processo saúdedoença (NOGUEIRA, 2009). Assim, a partir de novos cenários surgiriam novos enactments (MOL, 2002) - novas dramatizações na prática clínica e na produção da atenção à saúde. Por sua vez, esses novos enactments podem ser considerados como frutos de novas ideias, ou talvez de um novo estilo de pensamento médico (FLECK, 1986) capaz de ressignificar marcas e coisas (HACKING, 1992).

Este artigo é originário de uma pesquisa de pós-doutorado, desenvolvida no IMS-UERJ, que problematizou o processo de transformação da formação médica brasileira a partir da análise da experiência de reforma curricular da escola médica da Universidade Federal Fluminense. No estudo, elegeu-se o olhar como objeto de investigação e trabalhou-se com os conceitos de estilo de pensamento/coletivo de pensamento (FLECK, 1986). Utilizou-se, ainda, o conceito de arqueologia, no sentido foucaultiano do termo (FOUCAULT, 1987), com o propósito de esboçar uma "trajetória do olhar" do aprendiz médico - de uma formação (bio)médica tradicional para uma outra, que propõe mudanças. Desse modo, trabalhou-se com a correspondência contida no binômio "mudança de olhar / mudança de atitude", ao se considerar a existência de uma forte inter-relação entre o ver, o saber e o agir. 
Duas hipóteses nortearam a condução da pesquisa que subsidiou o estudo: 1 ${ }^{\text {a) }}$ A formação médica atual encontra-se estruturada / tensionada pelas proposições de dois projetos distintos: um projeto tecnocientífico e um projeto ético-humanista. $2^{\text {a) }}$ No Brasil se reconhece o SUS como superfície de emergência de novas demandas que podem alavancar as transformações requeridas na educação médica, com ênfase especial no papel desempenhado pela Atenção Básica neste processo.

Nas seções seguintes do artigo, apresentamos a criação da experiência médica moderna, descrita por Foucault, estabelecendo um contraponto com a proposição de Fleck sobre a emergência de um novo estilo de pensamento - de um olhar anatomoclínico para um olhar ampliado. Em seguida, introduzimos uma reflexão sobre as propostas de reorientação da formação médica brasileira, tomando como exemplo a experiência do atual currículo médico da UFF.

\section{Uma arqueologia do olhar: o saber e a prática médicos em perspectiva}

\section{O olhar anatomoclínico: a criação da experiência médica moderna}

Foucault inicia o prefácio de $O$ nascimento da clínica (1980) com uma sentença explicativa contundente sobre o seu projeto: "Este livro trata do espaço, da linguagem e da morte; trata do olhar”. A partir desse anúncio, constrói uma narrativa sobre o deslocamento histórico de uma medicina clássica, uma medicina fundamentalmente humoralista, cujo objeto é a doença como essência abstrata, para uma medicina anatomoclínica, uma medicina do corpo e das lesões. Tal deslocamento se processa, segundo o autor, em torno dos últimos anos do século XVIII, e significa uma ruptura de tamanha grandeza que permite à medicina "apresentar-se" como medicina científica.

Ao descrever a especificidade desse novo olhar, fundado na objetividade, Foucault explica de que forma essa reorganização conseguiu abarcar também o sujeito, tornando-o objeto de seu discurso:

O olhar não é mais redutor, mas fundador do indivíduo em sua qualidade irredutível. $\mathrm{E}$ assim torna-se possível organizar em torno dele uma linguagem racional. $\mathrm{O}$ objeto do discurso também pode ser um sujeito, sem que as figuras da objetividade sejam por isso alteradas. Foi esta reorganização formal e em profundidade, mais do que o abandono das teorias e dos velhos sistemas, que criou a possibilidade de uma experiência clinica: ela levantou a velha proibição aristotélica; poder-se-á, finalmente, pronunciar sobre o indivíduo um discurso de estrutura científica. (FOUCAULT, 1980, p. XIII) 
Camargo Jr. (2003) faz uma advertência sobre essa delimitação foucaultiana, argumentando que a mesma não é a única possível. Cita, por exemplo, Craveuil, que situa as raízes do pensamento e da prática médica contemporâneos na escola hipocrática. No entanto, concorda com o marco proposto por Foucault ao observar que a incorporação da anatomia patológica ao arsenal técnico-científico da medicina configura uma ruptura de tal importância que justifica sua adoção como marco: "a medicina do final do século XVIII e a do século XX são muito mais próximas entre si do que de qualquer dos seus antecedentes históricos, ainda que possam ter conservados elementos destes" (CAMARGO JR., 2003, p. 109).

Para Foucault, o aparecimento da clínica como fato histórico se revela na substituição da pergunta fundamental do médico para o doente: "o que é que você tem?", por uma outra: "onde lhe dói?" (FOUCAULT, 1980, p. XVIII).

Com o nascimento da clínica moderna, ver é equivalente a saber - a gênese da manifestação da verdade é também a gênese do conhecimento da verdade, afirma Foucault. Não mais existe diferença de natureza entre a clínica como ciência e a clínica como pedagogia. Em um grupo constituído pelo professor e seus alunos, "o ato de reconhecer e o esforço de conhecer se realizam em um único movimento" (FOUCAULT, 1980, p. 125).

Foucault (1980) aponta em seu texto algumas especificidades do olhar clínico nascente em contraposição ao olhar dos nosógrafos da tradição médica anterior, que ele denomina de "olhar de jardineiro", que procurava reconhecer, na variedade das aparências, a essência específica. Ao contrário, o novo olhar médico é um olhar da sensibilidade concreta, um olhar que vai de corpo em corpo. Portanto, a nova imagem da clínica é construída através de uma experiência exploratória do espaço tangível do corpo - local onde se ocultam segredos, invisíveis lesões e o próprio mistério das origens. A partir de então, a medicina dos sintomas regride e desponta a medicina dos órgãos, do foco e das causas, diante de uma clínica inteiramente ordenada pela anatomia patológica (FOUCAULT, 1980).

A narrativa de Foucault sobre o nascimento da clínica registra que, do início do Renascimento até o final do século XVIII, o saber da verdade fazia parte da observação da vida, mas a partir da experiência básica de anatomopatologista constituída por Bichat, processou-se um deslocamento em direção à observação da morte. Houve uma conversão do olhar médico, que passou a incluir a morte em seu conjunto técnico e conceitual, já que "a morte era a única possibilidade de 
dar à vida uma verdade positiva" (FOUCAULT, 1980, p. 166).

O grande corte na história da medicina data precisamente do momento em que a experiência clínica tornou-se o olhar anatomoclínico. Foucault apresenta o triunfo de Bichat através de sua exortação: "Abram alguns cadáveres: logo verão desaparecer a obscuridade que apenas a observação não pudera dissipar". E conclui a descrição desse processo com ma bela metáfora: "A noite viva se dissipa na claridade da morte" (Foucault, 1980, p. 168).

No processo de surgimento da anatomoclínica, delineado acima, consolidouse outra vertente na caracterização das doenças, não mais como um fenômeno vital, mas como a expressão de lesões celulares: "a nova concepção de doença passa a ser a categoria central do saber e da prática médica" (CAMARGO JR., 2003, p. 109). Segundo Luz (1988), através do deslocamento epistemológico de uma arte de curar indivíduos doentes para uma disciplina das doenças, a medicina ocidental tornou-se definitivamente uma "ciência das doenças". Ao instituir a doença e o corpo como objetos, excluindo do campo da cientificidade a vida, a saúde e a cura, a medicina incluiu-se na racionalidade científica moderna construída do século XVI ao século XIX.

A consolidação desse processo ocorreu a partir de profundas transformações no ensino e na prática médica. O hospital, local onde se tornou possível reunir em grande número as observações necessárias ao estabelecimento das descrições anatomopatológicas e a realização de necrópsias, transformou-se numa máquina de pesquisa e de ensino. A partir de então, o hospital se tornou fundamental para o ensino da medicina (CAMARGO JR., 2003).

\section{O estilo de pensamento segundo Fleck}

A epistemologia de Ludwig Fleck (1986) oferece significativa contribuição aos estudos referentes à medicina. Em seu livro $A$ gênese e o desenvolvimento de um fato científico, realiza um estudo sobre o desenvolvimento histórico da sífilis e da reação de Wasserman, demonstrando como os "fatos científicos" estariam condicionados às circunstâncias históricas e culturais. Nesse trabalho, o autor apresenta os conceitos de estilo de pensamento (a disposição para a percepção orientada, o observar e o ver formativo) e de coletivo de pensamento (a natureza coletiva da investigação, que seria o desenvolvimento coletivo do estilo de pensamento). 
Ao descrever o papel das práticas profissionais na construção e validação dos "fatos científicos", Fleck nos explica que o conhecimento não pode ser concebido fora do grupo de pessoas que o criam e o possuem. Um "fato" científico é como uma regra desenvolvida por um pensamento coletivo, isto é, um grupo de pessoas ligadas por um estilo de pensamento comum. O conceito de estilo de pensamento tenta abranger tanto os pressupostos a partir dos quais o grupo constrói seu estoque específico de conhecimento, quanto sua unidade conceitual e prática (LÖWY, 1994).

$\mathrm{Na}$ proposição de estilos e coletivos de pensamento, Fleck (1986) elucida o processo de instituição e manutenção de um estilo de pensamento dentro de um coletivo de pensamento, a consolidação e reprodução deste estilo com a conquista de novos adeptos, e a dificuldade de diálogo entre os diferentes estilos devido à incomensurabilidade de ideias. Nesse contexto, a ruptura revolucionária nada mais é do que a instauração e o desenvolvimento de outro estilo de pensamento.

De acordo com a reflexão sócio-filosófica desenvolvida por Fleck (1986), a educação seria uma instância modeladora dos sistemas de representação da realidade. Portanto, a introdução em um campo de conhecimento seria mais um doutrinamento do que um estímulo do pensamento crítico-científico. Partindo desse pressuposto, considera-se que todo aprendizado se dá através de uma necessária reorientação do olhar.

\section{Em busca de um olhar ampliado: a reorientação da formação médica}

Uma das razōes para os impasses verificados na prática médica contemporânea repousa no fato de que a medicina, por vezes chamada de "científica", é uma prática relacional. Em Biomedicina, saber e ciência: uma abordagem critica, Camargo Jr. (2003) apresenta uma discussão bastante abrangente sobre a relação entre a medicina - saber e prática - e a ciência.

Canguilhem já problematizava esta relação em O normal e o patológico (1990), ao afirmar que a medicina, muito mais do que uma ciência propriamente dita, é uma técnica ou uma arte situada na encruzilhada de várias ciências: "Ocorre com a medicina o mesmo que com todas as técnicas... Eis por que, sem ser ela própria uma ciência, a medicina utiliza os resultados de todas as ciências a serviço das normas da vida" (CANGUILHEM, 1990, p. 188). 
Vale a pena recorrer a outra afirmação de Canguilhem, tantas vezes citadas nos textos acadêmicos, sobre a associação entre clínica e ciência:

\footnotetext{
Ora, a clínica não é uma ciência e jamais o será, mesmo que utilize meios cuja eficácia seja cada vez mais garantida cientificamente. A clínica é inseparável da terapêutica, e a terapêutica é uma técnica de instauração ou de restauração do normal, cujo fim escapa à jurisdição do saber objetivo, pois é a satisfação subjetiva de saber que uma norma está instaurada. (CANGUILHEM, 1990, p. 185).
}

Nos seus Escritos sobre a medicina (2005), Canguilhem formula uma série de críticas sobre a razão médica nas sociedades contemporâneas, na qual a medicina se empenhou para se tornar uma ciência das doenças, tais como: a dissociação progressiva entre a doença e o doente, o tratamento dos doentes como objetos e não como sujeitos de sua doença e o desinteresse pelas tentativas de compreensão do papel e do sentido da doença na experiência humana.

Através de uma perspectiva vitalista, Canguilhem aborda a doença de forma peculiar, inserindo-a na história pessoal do ser humano: "As doenças do homem não são somente limitações de seu poder físico, são dramas de sua história” (CANGUILHEM, 2005, p. 63). O autor questiona, ainda, a ilusão de subjetividade dos médicos ao confiarem nos fundamentos estritamente objetivos de seus conselhos e desprezarem a importância da relação entre o médico e o doente no exercício da prática clínica, considerando-a uma relação ativa, que pode ser positiva ou negativa. Apesar de essa relação ter sido considerada, na idade positivista da medicina, um resíduo arcaico de magia ou de fetichismo, Canguilhem chama a atenção para a utilidade de sua reatualização, creditando à psicanálise o pioneirismo nessa empreitada (CANGUILHEM, 2005).

No Brasil, o campo da Saúde Coletiva trouxe à tona a discussão sobre a integralidade das ações de saúde, reacendendo o debate sobre as práticas de cuidado integrais e as possibilidades de construção de uma clínica ampliada (CAMPOS, 2007), na medida em que se tornou consensual a importância dessa reflexão para a realização de um trabalho em saúde humanizado e mais resolutivo.

O trabalho em saúde é uma atividade essencialmente relacional. O cuidado, núcleo comum da ação de todas as profissōes de saúde, é utilizado como categoria analítica fundamental para uma formação profissional em saúde orientada sobre as premissas da integralidade: "o cuidado no campo da saúde é sua própria razão de ser, é o meio e o fim das ações desenvolvidas pelos profissionais que atuam nesse 
campo" (SILVA JUNIOR et al., 2006, p. 93). De forma complementar, Merhy (2004) afirma, ao desenvolver uma tipologia das tecnologias em saúde, que parte essencial do trabalho em saúde se inscreve nas denominadas "tecnologias leves" (que dizem respeito às relações).

O trabalho médico, que utiliza a doença como categoria central, faz parte de um "estilo de pensamento médico (ou biomédico)", isto é, de um modo distinto de definir a realidade do adoecimento (CAMARGO JR., 2003). Por outro lado, as propostas de reorientação da formação profissional em saúde buscam organizar as práticas profissionais a partir de um referencial mais abrangente - as necessidades de saúde da população -, em sincronia com os princípios ético-políticos da Reforma Sanitária brasileira e com os princípios do Sistema Único de Saúde (SUS).

Sob a perspectiva arqueológica foucaultiana, pode-se considerar o Movimento Sanitário brasileiro como um acontecimento discursivo que, aliado a um conjunto de discursos mundialmente produzidos sobre a necessidade de uma reorientação da formação médica (FEUERWERKER, 2006), estabeleceram as condições de possibilidade para a materialização de propostas, como, por exemplo, a preconizada pelas novas Diretrizes Curriculares do Ensino Médico no Brasil (2001). Um dos principais objetivos dessas novas diretrizes seria a ampliação do olhar médico para além da ótica estritamente biológica, visando a uma melhor resolutividade dos problemas de saúde da população.

Esta proposta de reorientação ocorreu em consonância com a estratégia de reorientação do modelo assistencial adotada pelo Ministério da Saúde, com ênfase na Atenção Básica (em especial o Programa Saúde da Família), devido à necessidade de se buscar uma prática clínica ampliada e integradora das dimensōes biopsicossociais do adoecimento. Enfim, uma reconsideração, tanto das subjetividades presentes no complexo processo do adoecer humano, quanto da medicina como prática relacional.

\section{O quadro metodológico da investigação}

As reflexóes aqui apresentadas originaram-se de um estudo realizado na escola médica da Universidade Federal Fluminense (UFF), sede de uma reforma curricular implementada em 1994. Desenvolveu-se uma pesquisa de caráter etnográfico, entre 2007 e 2008, enfocando a disciplina Trabalho de Campo 
Supervisionado (TCS), considerada inovadora por se desenvolver em campos

de prática diversificados (SAIPPA-OLIVEIRA et al., 2004), com triangulação de métodos: observação participante dos novos cenários de aprendizagem, entrevistas com alunos e preceptores e análise documental.

Foram observadas a experiência de três grupos de alunos, conduzidos por seus preceptores, nos dois primeiros anos de formação. No primeiro ano, em TCS I, observou-se um grupo do primeiro período que trabalhava com o tema do envelhecimento e um grupo do segundo período que enfocava a Aids sob a perspectiva da integralidade. No segundo ano, em TCS II, observou-se a experiência de um grupo de alunos do terceiro período numa unidade básica de saúde. Paralelamente à observação etnográfica, foram entrevistados alunos e preceptores dos grupos observados. Realizou-se também uma análise documental que agregou os programas dos cursos, os artigos e vídeos produzidos sobre a reforma curricular.

A pesquisa foi aprovada pelo Comitê de Ética do Instituto de Medicina Social da UERJ (CAEE - 0111.0.258.259-07). Todos os atores participantes e entrevistados da pesquisa foram informados sobre seus objetivos e convidados a participar voluntariamente da mesma, com a apresentação de um Termo de Consentimento Livre e Esclarecido.

\section{A construção de um olhar ampliado}

\section{Um novo ritual de iniciação}

As experiências com dissecações anatômicas constituem o início de uma intervenção médica direta sobre o corpo humano, através da observação como fonte de conhecimento, e coincidem com o relato de Foucault (1980) sobre a inauguração de um (novo) olhar constituinte da medicina moderna.

Com a Anatomia, aprende-se simultaneamente a olhar (o corpo bumano especificamente) e a não olhar (o sujeito e sua história pessoal). Quando um estudante de medicina é interrogado sobre o impacto exercido pela Anatomia, através do contato com o cadáver, a resposta mais frequentemente obtida é a seguinte: "o cadáver não parece uma pessoa”. É o resultado da tarefa de "despersonalização do cadáver", assim nomeada pelos estudiosos do assunto. Na verdade, a importância que a Anatomia assume para a maior parte dos estudantes de medicina deve-se à experiência de ver o corpo humano, mesmo que o aprendizado se processe através 
de pura memorização. A necessidade empírica de ver literalmente, somada à intervenção através da dissecação, se tornam experiências tão fortes que fazem com que a Anatomia se destaque em relação às outras disciplinas (OLIVEIRA, 1992).

Uma das conclusões do estudo de Oliveira (1992) é que o currículo tradicional, tão resistente às mudanças, pode em parte estar condicionado por uma proposta implícita de encobrimento da morte, tanto por sua banalização, através de sua exibição permanente e exaustiva, como por sua desaparição através de um discurso estático e impessoal sobre a doença. Tal conclusão problematiza a natureza desse contato com a morte, ao reforçar a tese de que o estudo da Anatomia viabiliza muito mais um contato direto com o corpo humano, através do cadáver, do que com a experiência existencial da morte, ao contrário do que pensa o senso comum.

Em O normal e o patológico (1990), Canguilhem afirma que a razão positiva inicial para o exame do cadáver é o estudo da patologia. Com isto se perde a busca de solução para o sofrimento humano e não se propicia ao estudante a experiência da prática cotidiana de uma medicina que ofereça atenção pessoal aos doentes. Assim, o jogo de opostos que informa a prática médica - conhecer a doença para poder conceituar a saúde e estudar no morto as alterações que permitirão reconhecer o processo vital do adoecimento - desaparece no processo de aprendizagem do estudante sob uma vivência quase que única da doença e da morte.

No desenho da proposta do novo currículo da graduação em Medicina da UFF, a introdução da disciplina Anatomia, tradicionalmente oferecida no início dos cursos médicos, é protelada para o segundo período, no segundo semestre do primeiro ano. Criou-se, assim, um espaço para que o estudante possa desenvolver um olhar para a complexidade da vida humana e para o sujeito em relação, antes de introduzi-lo numa experiência orientada pela uniformidade da morte e pelos cadáveres do anfiteatro anatômico.

A maioria dos alunos entrevistados fez uma avaliação positiva desse deslocamento da Anatomia para o segundo período, mesmo reconhecendo a importância da Anatomia na formação médica. $\mathrm{Na}$ "semana de recepção do calouro de medicina da UFF", o enfoque sobre a determinação social do processo saúde-doença marca a diferenciação daquela formação - os alunos são levados a conhecer o município e uma unidade do Programa Médico de Família. Constrói-se, portanto, um novo ritual de iniciação - uma iniciação através da vida e das relações. 


\section{O polo ético-humanista em destaque}

De forma unânime, o discurso dos alunos entrevistados do primeiro período, ao traçarem um perfil do que seria um "médico ideal”, ressaltou a importância do polo ético-humanista na formação médica:

Para mim o mais importante é o lado humano, é lidar com o paciente sabendo que ele é uma pessoa, que tem uma história, e não ignorar isso. (Aluna 1)

O lado humanitário, eu acho o principal; o conteúdo a gente vai adquirindo aos poucos. O médico ideal para mim é aquele que é humano, que sabe lidar bem com o paciente, sabe conversar, é sociável e que tenha o conteúdo associado para ligar tudo. (Aluno 2)

Às vezes não precisa ter conhecimento extraordinário... O principal é isso: o carinho, a atenção ao paciente. Muitas vezes o paciente precisa de alguém para conversar e só relata algumas coisas para o médico... é a confiabilidade. (Aluno 3)

Quando falaram sobre as expectativas em relação ao que uma faculdade de Medicina pode oferecer para que se tornem bons médicos, as questões éticas e humanas, trabalhadas nas disciplinas Trabalho de Campo Supervisionado I e Saúde e Sociedade, foram enfatizadas:

Eu achava que ia chegar aqui, aprender daquela forma seca e a parte humanitária do médico ia vir de mim mesmo. Mas eu estou recebendo mais do que eu esperava de Trabalho de Campo e Saúde e Sociedade. A gente aprende muita coisa, vê muita coisa, isso fica na nossa cabeça. (Aluno 2)

A percepção sobre o processo saúde-doença referida pelos alunos condiz com a lógica mais ampliada que orienta o atual currículo da escola médica da UFF. Ao serem perguntados sobre o que consideravam um "problema de saúde", as respostas foram bem mais abrangentes do que a estreita visão biologizante proporcionada pela ótica biomédica:

Problema de saúde é quando tem alguma coisa funcionando errado no nosso organismo, seja por uma alimentação inadequada, pelo psicológico abalado... Saúde não é só corpo, é a mente, é a sociedade que você não está inserido corretamente. (Aluna 1)

Embora muita gente ache que a saúde seja um dano físico, que se resolve com medicamento, eu acredito que vai muito além disso. É o acesso às condições de educação, alimentação, tudo isso vai interferir na sua saúde direta ou indiretamente. (Aluno 3)

Um dos alunos fez referência à frase - "saúde não é determinada por um único elemento” - que ele escutou de um professor e que se tornou fundamental para sua elaboração de um conceito mais ampliado de saúde, conceito este que envolve desde as questôes de direito e cidadania até às condições de vida e acesso aos serviços de saúde. 
A partir do segundo período, entram em cena as disciplinas que compõem o bloco morfológico, sob a rubrica de Morfologia I (Anatomia, Embriologia e Histologia), além de Imunobiologia. Do período anterior permanecem as disciplinas Trabalho de Campo Supervisionado e a segunda parte de Saúde e Sociedade. Na metade do período, inicia-se a disciplina de Epidemiologia.

As três alunas entrevistadas do segundo período consideraram que, de um modo geral, as chamadas "disciplinas científicas" são as mais importantes para a formação médica, como Bioquímica, no primeiro período, e Anatomia e Imunobiologia, no segundo. No entanto, duas dessas alunas fizeram, em seguida à hierarquização de importância que conferia supremacia às disciplinas biológicas sobre as demais, algumas ressalvas que relativizaram de certa forma suas opiniōes anteriores:

Anatomia é essencial, todo médico tem que saber. Saúde e Sociedade e Trabalho de Campo te apresentam o Sistema de Saúde. Vamos considerar que, depois de Anatomia, Saúde e Sociedade e Trabalho de Campo são as mais importantes. (Aluna 5)

Eu gosto mais de Trabalho de Campo, porque é um espaço que a gente tem para pensar e descansar um pouco do resto. Não é só decorar, eu penso um pouco ainda. É importante pensar e formar opinião. Em Anatomia eu não faço isso, eu decoro nomes." (Aluna 6)

Houve divergência de opiniōes, entre as entrevistadas do segundo período, sobre qual seria o perfil e os atributos de um "bom médico". Uma delas afirmou que o bom médico é aquele que tem a capacidade de se relacionar bem com o outro:

Saber falar e saber ouvir a linguagem do outro. (Aluna 6)

A fala de outra aluna mostra oposição entre o desenvolvimento de habilidades relacionais e a parte "científica" da medicina, como se esta última inviabilizasse, ou dificultasse, de certa forma, o desenvolvimento da primeira:

Tem que ser atencioso, preocupado em ajudar a pessoa ali na hora. Tem que entender as pessoas, mas é que a medicina tem uma parte científica pura que eu gosto... (Aluna 4)

A contradição evocada por esta aluna traz à tona a questão dos impasses da prática clínica atual - eixo fundamental para as reflexões sobre a implementação de mudanças efetivas na formação médica. Mais especificamente, o foco desses impasses gira em torno das tensões existentes entre a aquisição de conhecimento científico e o desenvolvimento de uma sabedoria prática.

De pleno acordo com Canguilhem, nas suas reflexões sobre medicina e ciência, Hunter (1996) afirmou que a medicina clínica, diferentemente de outras 
áreas das ciências humanas, não reconheceu seu caráter interpretativo, nem as

regras que usa na negociação de seus significados. No afã de se perceber como uma ciência, esclareceu Hunter (1996), a clínica não compreende teoria e prática de um modo único, permitindo que se estabeleça uma tensão entre a episteme (o conhecimento científico), que funciona através de objetos estáveis e generalizáveis do conhecimento, e a phronesis (razão prática), que opera através de um tipo de conhecimento utilizado quando os objetos são mutáveis ou ideográficos. $\mathrm{Na}$ abordagem de casos particulares, característica do processo de trabalho na medicina, que é orientada por um paradigma indiciário (GINZBURG, 1989), a episteme, ou a razão científica, é demasiadamente generalizante e abstrata para dar conta do caso clínico.

Portanto, o conhecimento clínico, quando aplicado ao cuidado das pessoas, deve necessariamente incorporar um saber moral e interpretativo, ou seja, uma "razão ou sabedoria prática". A dimensão hermenêutica da clínica manifestase, segundo Hunter (1996), mesmo diante de situações nas quais as evidências científicas generalizantes e reprodutíveis encontram-se disponíveis - pois o médico sempre precisa fazer escolhas e adequações para aplicação em um caso individual.

Outro elemento importante a ser examinado neste estudo - se o polo éticohumanista da medicina poderia, ou não, ser transmitido através da formação foi abordado no discurso dos alunos. Uma das alunas entrevistadas do segundo período disse acreditar que a "sensibilidade humana" é uma virtude inata, que não pode ser ensinada:

Eu acho que tem que ter uma coisa que não se aprende em livro, nem na faculdade, que é uma certa sensibilidade, que é da pessoa... A faculdade tem de fornecer conteúdo teórico e meios para que eu possa colocar essa teoria toda em prática. (Aluna 5)

Essa crença reproduz a tão difundida noção de dualidade entre teoria e prática, ao mesmo tempo em que reforça a preponderância de uma tradicionalíssima ideia de que o processo de aprendizagem deve girar em torno dos aspectos exclusivamente teóricos do conhecimento. Outra aluna entrevistada, ao falar sobre a disciplina Trabalho de Campo Supervisionado, deixou no ar uma interrogação: "Será que não é a hora de meter a cara no livro e deixar a prática para mais tarde?”

Em contraposição a este questionamento, a opinião de todos os outros estudantes entrevistados foi extremamente favorável à inserção de atividades práticas desde o início da formação, reforçando o potencial de Trabalho de 
Campo Supervisionado na construção de novos olhares. Algumas expressōes literalmente refletem a mudança de olhar: "hoje eu tenho uma visão diferente"; "eu entro com uma visão e devo sair com outra". Outras falas mostram como o estágio prático desenvolveu a capacidade de escuta e as habilidades relacionais: "a gente vai ouvindo e vai aprendendo a ouvir também"; "TCS modela a nossa prática desde o começo, prepara o aluno para o contato com o paciente".

O enfoque prático e dinâmico da disciplina TCS foi bastante valorizado pelos alunos. As críticas vieram de grupos cujas atividades foram mais teóricas do que práticas. Um dos entrevistados fez comentários sobre a experiência negativa de outros grupos: "O que eu ouço dos meus amigos de outros grupos, têm uns que são muito teóricos, eles ficam só em sala de aula lendo texto. Eu acho importante a gente visitar os lugares porque é prático - a gente vê o que está acontecendo ali”. Note-se que a experiência de ver é formativa e continua sendo fundamental para o estudante de medicina.

Um comentário interessante da preceptora de TCS I, fruto da observação dos comportamentos e sentimentos dos alunos, mostrou a importância do desenvolvimento de tecnologias relacionais para a identidade do médico: "O que acaba ficando claro, é que eles começam a se sentir médicos. O aluno se imagina médico quando está em relação. Poucos se imaginam médicos em um laboratório, com uma lâmina”.

Ao indicar que o desenvolvimento de uma clínica ampliada não depende apenas da disposição dos elementos técnico-operacionais envolvidos na aplicação de um tipo de modelo de atenção ou de organização das práticas em saúde, Favoreto (2007) aponta como imperioso que essa trajetória seja acompanhada de uma revalorização dos saberes práticos e da incorporação de "saberes não biomédicos". Admite ser necessário construir uma "teoria da prática”, ou seja, um processo que vá além das características pessoais e morais do médico. Desse modo, as habilidades e competências aprendidas deveriam se formar como questôes intrínsecas ao cuidado em saúde: "Essas competências passariam, assim, a compor a clínica e não persistiriam como elementos externos, como parentes distantes da necessidade de qualificar e tornar mais próxima e efetiva a relação de médicos e pacientes no encontro clínico" (FAVORETO, 2007, p. 204). Nesse sentido, é possível considerar a clínica como um campo de produção de saberes que se forma quando o olhar do médico se volta para os sujeitos e suas narrativas 
no encontro clínico. Esse processo só poderá ser construído com sucesso a partir

da consideração do indivíduo doente como Sujeito e de uma abordagem desse Sujeito em seu contexto e em suas relações intersubjetivas.

Uma das principais revelaçôes deste estudo foi a de que esse "novo olhar", que poderá resultar em um "novo agir", é passível de ser reproduzido através de treinamento. Daí a relevância de se pensar a educação médica em outros modos e estilos - em proposições que resgatem o esquecido polo ético-humanista.

\section{Um olhar sobre o sujeito}

$\mathrm{Na}$ atualidade, cada vez mais ganha força a noção de que uma formação médica com enfoque exclusivo nas disciplinas biológicas é insuficiente para a apreensão da complexidade e da singularidade do adoecimento humano. Pressupõe-se que as ciências sociais e humanas podem oferecer uma contribuição importante para essa formação - através de referências para uma compreensão ampliada do processo saúde-doença e para a organização do cuidado em saúde.

Na experiência da disciplina TCS I (grupo do $1^{\circ}$ período) com o tema do envelhecimento, as principais atividades desenvolvidas foram: discussão de textos, filmes e dramatizações em sala de aula; entrevistas com idosos próximos; visita aos asilos; visita a um espaço de cursos e atividades artísticas (Oficina de Teatro e da Memória); e visita a um centro de convivência que oferece atividades artísticas para idosos (Oficina de Artesanato e de Cerâmica).

A compreensão do processo do envelhecimento em cenários da vida real e a reflexão sobre a situação do idoso na sociedade e nos serviços de saúde permitiram que os alunos construíssem um olhar sobre o Sujeito. Como consequência da construção desse olhar ampliado em relação aos idosos, novas atitudes e disposições puderam emergir entre os alunos. Verificou-se, então, que a mudança de visão sobre o envelhecimento, proporcionada por essa disciplina, gerou uma mudança de atitude frente aos idosos, tais como: quebra de preconceitos; novos pontos de vista sobre o envelhecimento; um olhar para os problemas existenciais dos idosos; a reconstrução do espírito coletivo e a mobilização de sentimentos.

Durante a observação etnográfica do campo de TCS I que tematizava a Aids, o cenário que serviu de base para as atividades do grupo do segundo período foi a Coordenação de Aids do HUAP. De forma complementar, os cenários das organizações não governamentais (ONGs) ligadas à Aids também fizeram parte da 
experiência do grupo, como, por exemplo, o Grupo Pela Vidda (RJ) e a Sociedade Viva Cazuza, que foram visitadas ao longo do período observado. Verificou-se no discurso dos alunos a sedimentação de uma premissa fundamental para uma abordagem integral da Aids - a importância de se organizar o atendimento a partir de uma estratégia usuário-centrada, através do trabalho integrado de uma equipe interdisciplinar. A partir da experiência de observação dos atendimentos na Coordenação de Aids e dos depoimentos de ativistas das ONGs visitadas, foram valorizadas as questóes intersubjetivas, tais como o envolvimento, a troca e a escuta qualificada. A questão do preconceito em relação às pessoas soropositivas (com HIV/Aids) chamou a atenção dos alunos, sensibilizando-os para as dimensões humanas e éticas do ato de cuidar.

A proposta de TCS I favorece o polo ético-humanista da formação, contribuindo não só para a promoção do resgate da dimensão cuidadora, mas também para a valorização da medicina como prática essencialmente relacional. Ao enfatizar o desenvolvimento das tecnologias relacionais na formação médica, as práticas pedagógicas utilizadas em TCS I focaram-se em três importantes eixos de atuação: ampliação e reorientação do olhar para as subjetividades do processo saúde-doença; ampliação da capacidade de escuta e ampliação da capacidade dialógica.

$\mathrm{Na}$ avaliação da disciplina TCS I, merece destaque a reivindicação principal dos alunos: mais campos de prática e menos leitura de textos. As principais críticas dirigiam-se à carga horária da disciplina, que ocupava dois turnos na semana e era considerada excessiva pela maioria.

\section{Um olhar sobre a produção do cuidado na Atenção Básica}

Nos desenhos tradicionais de estágios práticos nos serviços da rede básica de saúde, os estudantes eram levados para conhecer os serviços de saúde localizados na periferia sem qualquer envolvimento ou responsabilidade, transformando as unidades em verdadeiros "zoológicos" - locais onde se podiam observar equipes e pacientes periféricos e pobres (SILVA JUNIOR et al., 1996).

$\mathrm{Na}$ observação etnográfica de uma unidade básica de saúde do município de Niterói, cenário da disciplina TCS II, descrita neste trabalho, não se verificou esta indesejável situação. Ao contrário, observou-se uma participação efetiva 
do preceptor nas atividades desenvolvidas no cotidiano daquela unidade, em paralelo com sua função docente. As várias situações oferecidas pelo campo foram devidamente exploradas como material de ensino e de produção de conhecimento. Os alunos mostraram-se preparados para lidar com as demandas do campo de forma responsável e ética, além de reconhecerem a importância do trabalho ali desenvolvido para a formação profissional de um médico.

Através das vivências em uma unidade básica de saúde, os alunos puderam assimilar de forma prática alguns conceitos-chave para se pensar a produção do cuidado em saúde, como: necessidades de saúde, processo de trabalho, modelo assistencial, acolhimento, integralidade e trabalho em equipe. Em seus discursos, havia clareza sobre o que seria um atendimento centrado no paciente e como se construía um projeto terapêutico singular. Puderam conhecer ferramentas valiosas para o desenvolvimento de uma clínica ampliada, entrar em contato com a diversidade da cultura popular, compreender a morbidade e a mortalidade sob o ponto de vista coletivo, conhecer o sistema de informação da unidade, refletir sobre o papel da intersetorialidade na produção da saúde e identificar programas e ações de saúde coletiva.

Em linhas gerais, foram identificados quatro grandes eixos de atuação da disciplina TCS II: abordagem do Sujeito em seu contexto social; ampliação da clínica; construção de vínculos e trabalho em equipe interdisciplinar.

$\mathrm{O}$ preceptor de TCS II apontou as questôes centrais que interferiam negativamente na utilização da rede pública de saúde como um campo de práticas: a instabilidade da parceria com a Secretaria Municipal de Saúde e a falta de adesão dos médicos das unidades de saúde no processo de formação dos alunos. Por sua vez, os alunos criticaram o número reduzido de preceptores, que fazia com que os grupos ficassem muito grandes, dificultando a observação e prejudicando o aproveitamento.

\section{Considerações finais}

A concepção de doença como um acometimento orgânico que deixa marcas no corpo - as lesões - faz parte de um estilo de pensamento médico (ou biomédico). Apesar de se tratar de uma categoria construída, um artefato do conhecimento, tal construção passa continuamente despercebida e a tendência que se verifica na prática é a de uma indesejável reificação dessa categoria. Na sociedade ocidental, 
essa forma de olhar - o olhar anatomoclínico - ainda é identificada como verdadeira, objetiva e científica (CAMARGO JR., 1998).

Hacking (1992) propõe uma tríade classificatória - ideias, marcas e coisas - para os elementos contidos nas ciências laboratoriais. Aplicando este referencial analítico à formação médica tradicional, compõe-se um quadro que pode ser descrito da seguinte maneira: a objetivação dos problemas de saúde como "ideia” principal, a díade doença-lesão como "coisas" e os instrumentos da tecnologia diagnóstica (os exames complementares) representando as "marcas". Em propostas reformistas, outro arranjo classificatório pode ser esboçado: a percepção do sujeito doente seria a "ideia" central; as dimensões subjetivas presentes no adoecimento seriam os novos "marcadores" e a valorização do uso das tecnologias relacionais inverteria a "ordem das coisas” nesse processo. Ou seja, nas propostas de transformação do ensino médico, como é o caso da experiência analisada neste estudo, os vários contextos de aprendizagem oferecidos pela diversidade dos campos de prática concorreriam para transformar as ideias e ressignificar marcas e coisas.

Considerando que inovações no processo de trabalho possibilitam mudanças na prática clínica e na produção da atenção à saúde, os resultados da estratégia de reorientação da formação médica na UFF apontam para uma inovação na produção do cuidado, que, por sua vez, remeteria a um processo de inovação no estilo de pensamento biomédico hegemônico. Apesar do mérito inquestionável dessas inovaçôes, por responderem positivamente a muitos dos impasses e paradoxos da clínica tradicional, seria temerário aventar a hipótese de uma mudança de estilo de pensamento médico no sentido fleckiano do termo. Além das inúmeras dificuldades institucionais existentes e da necessidade de participação da sociedade para a consolidação desse processo, leva-se um tempo para que essas inovações sejam internalizadas pelos estudantes, passem a fazer parte do imaginário social do médico e criem condiçóes de possibilidade para o surgimento de uma nova clínica. Tais inovações podem ser vistas como estratégias contra-hegemônicas que operam no nível molecular, no espaço dos micropoderes, com potência, mesmo que no longo prazo, para redimensionar a clínica, ampliando as possibilidades de resolução dos problemas de saúde (NOGUEIRA, 2012).

A perspectiva epistemológica adotada neste trabalho propiciou uma reflexão crítica e enriquecedora sobre o tema em questão, mas é importante estabelecer uma articulação com a hipótese complementar em prol da complexidade das dinâmicas sociais em jogo. 
$\mathrm{Na}$ hipótese complementar, consideramos o SUS como superfície de emergência de novas demandas que podem alavancar as transformações requeridas na educação médica brasileira. Há uma disputa viva de projetos, lógicas e imaginários que influenciam o processo de mudança na educação médica. Se a ideologia médica tradicional é produzida pelas relações sociais, as transformações não poderão ocorrer independentemente da conjuntura social. A lógica da produção do cuidado em saúde proposta pelo SUS não é uma ideia hegemônica em nossa sociedade e requer mudanças profundas no processo de trabalho e na formação dos profissionais de saúde. De certa forma, o SUS disputa um imaginário social com a lógica do consumo, ativamente produzida nas sociedades capitalistas. $\mathrm{Na}$ maior parte das vezes, a lógica do SUS é totalmente atravessada pelos interesses do complexo médico-industrial, que investe fortemente na incorporação tecnológica dura. Entretanto, mesmo envolvido por toda essa teia de interesses e contradições, o SUS pode ser considerado como superfície de emergência das mudanças na formação médica, especialmente em relação aos novos cenários de prática - estratégia amplamente difundida na maioria das escolas médicas brasileiras (NOGUEIRA, 2012).

\section{Referências}

BRASIL. Ministério da Educação. Resolução CNE/CES no 4/2001. Diretrizes Curriculares Nacionais do Curso de Graduação em Medicina. Diário Oficial da União. Brasília, 09 de novembro de 2001, seção 1, p. 38.

CAMARGO JR., K.R. Medicina, médicos, doenças e terapêutica: exame crítico de alguns conceitos. Rio de Janeiro: UERJ/IMS, 1998 Série Estudos em Saúde Coletiva, 170).

. Biomedicina, saber \& ciência: uma abordagem crítica. São Paulo: Hucitec, 2003.

. A filosofia empírica da saúde. In: CAMARGO JR., K.R.; NOGUEIRA, M.I. (Orgs.) Por uma filosofia empírica da atenção à saúde: olhares sobre o campo biomédico. Rio de Janeiro: Fiocruz, 2009. p. 13-26.

CAMPOS, G.W.S. Saúde Paideia. São Paulo: Hucitec, 2007. (Saúde em Debate, 150).

CANGUILHEM, G. O normal e o patológico. Rio de Janeiro: Forense Universitária, 1990.

Escritos sobre a medicina. Rio de Janeiro: Forense Universitária, 2005 (Col. Fundamentos do Saber).

CUNHA, G.T. A construção da clínica ampliada na atenção básica. São Paulo: Hucitec, 2005. FAVORETO, C.A.O. A narrativa na e sobre a clínica na atenção primária: uma reflexão sobre o modo de pensar e agir dirigido pelo diálogo à integralidade e ao cuidado em saúde. 
Tese (Doutorado em Saúde Coletiva) - Instituto de Medicina Social, Universidade do Estado do Rio de Janeiro, Rio de Janeiro, 2007.

FEUERWEKER, L.C.M. O movimento mundial de educação médica: as Conferências de Edinburgh. Cadernos da ABEM, v. 2, jun. 2006.

FLECK, L. La génesis y el desarrollo de um hecho científico. Madrid: Alianza Editorial, 1986. FOUCAULT, M. O nascimento da clínica. Rio de Janeiro: Forense Universitária, 1980. . A arqueologia do saber. Rio de Janeiro: Forense Universitária, 1987.

GINZBURG, C. Sinais: raízes de um paradigma indiciário. In: Mitos, emblemas, sinais. São Paulo: Companhia das Letras, 1989.

HACKING, I. The self-vindication of the laboratory sciences. In: PICKERING, A. (Ed.). Science as practice and culture. Chicago: The University of Chicago Press, 1992. p. 29-64.

HUNTER, K.M. Narrative, literature and the clinical exercise of practical reason. The Journal of Medicine and Philosophy, v. 21, p. 303-320, 1996.

LÖWY, I. Fleck e a historiografia recente da pesquisa biomédica. In: PORTOCARRERO, V. (Org.). Filosofia, história e sociologia das ciências I: abordagens contemporâneas. Rio de Janeiro: Fiocruz, 1994. p. 233-249.

LUZ, M. T. Natural, racional e social: razão médica e racionalidade científica moderna. Rio de Janeiro: Campus, 1988.

MERHY, E.E. et al. O trabalho em saúde: olhando e experienciando o SUS no cotidiano. São Paulo: Hucitec, 2004.

MOL, A. The body multiple. Durham: Duke University Press, 2002.

NOGUEIRA, M.I. As mudanças na educação médica brasileira em perspectiva: reflexões sobre a emergência de um novo estilo de pensamento. Revista Brasileira de Educação Médica, v. 33, n. 2, p. 262-270, 2009.

. Retratos da formação médica nos novos cenários de prática. São Paulo: Hucitec, 2012. (Saúde em Debate, 220).

OLIVEIRA, J.A. Educación y asistencia médica: su postura implícita ante la muerte. Revista Mexicana de Educación Médica, v. 3, n. 1, 1992.

RIBEIRO, E.C.O. Educação permanente em saúde. In: MARINS, J.J.N. et al. (Orgs.). Educação médica em transformação: instrumentos para a construção de novas realidades. São Paulo: Hucitec, 2004. p. 285-303.

SAIPPA-OLIVEIRA, G.; KOIFMAN, L.; MARINS, J.J.N. A busca da integralidade nas práticas de saúde e a diversificação dos cenários de aprendizagem. O direcionamento do curso de medicina da UFF. In: PINHEIRO, R.; MATTOS, R. A. (Orgs.) Cuidado: as fronteiras da integralidade. Rio de Janeiro: Cepesc, 2004. p. 307-319. 
SILVA JUNIOR, A. G.; PIRES, A. C.; MARINS, J. J. N.; TOMASSINI, H. C. B. As experiências de articulação universidade-serviço-sociedade em Niterói, RJ. Divulgação no 12 - Niterói, Julho de 1996. [mimeo].

SILVA JUNIOR, A.G.; PONTES, A.L.M.; HENRIQUES, R.L.M. O cuidado como categoria analítica no ensino baseado na integralidade. In: PINHEIRO, R.; CECCIM, R.B.; MATTOS, R.A. (Orgs.) Ensinar saúde: a integralidade e o SUS nos cursos de graduação na área da saúde. Rio de Janeiro: Cepesc, 2006. p. 93-110. 


\section{Abstract}

\section{The reconstruction of medical education within new practice sceneries: a new thinking style?} This article debates the transformation process of the Brazilian medical education based on the experience of the curriculum reformation developed in the Medical School of Universidade Federal Fluminense. We adopted Ludwig Fleck's socio-philosophical reference, assuming that the anatomoclinical viewpoint guides the biomedic thinking style. It was considered the hypothesis that the medical education finds itself structured between two poles: the technical-scientific and the ethical-humanist, the former being more appreciated, and that Brazil's Unified National Health System (SUS) as the platform for the emergence of changes in medical education. A study with ethnographic features was conducted focusing on the subject of "Supervised Fieldwork", with the following methods being triangulated: partaker observation of diversified learning sceneries throughout the first two years of education; interviews with student and preceptors; and document analysis. We concluded that the establishment of new practice scenarios favors the construction, by the students, of an amplified point of view about the health services users, which contributes for the rescue of the ethical-humanist pole of education.

Key words: medical education; epistemology; practice scenarios; Brazil's Unified National Health System. 